\title{
The HIF1a-PDGFD-PDGFRa axis controls glioblastoma growth at normoxia/mild- hypoxia and confers sensitivity to targeted therapy by echinomycin
}

Gong Peng ${ }^{1 \dagger}$, Yin Wang ${ }^{2 \dagger}$, Pengfei Ge ${ }^{3}$, Christopher Bailey ${ }^{2}$, Peng Zhang ${ }^{4}$, Di Zhang ${ }^{5}$, Zhaoli Meng ${ }^{1}$, Chong Qi ${ }^{1}$, Qian Chen ${ }^{1}$, Jingtao Chen ${ }^{1}$, Junqi Niu', Pan Zheng ${ }^{2,6}$, Yang Liu ${ }^{2,6^{*}}$ and Yan Liu ${ }^{2^{*}}$

\begin{abstract}
Background: Glioblastoma multiforme (GBM), a lethal brain tumor, remains the most daunting challenge in cancer therapy. Overexpression and constitutive activation of PDGFs and PDGFRa are observed in most GBM; however, available inhibitors targeting isolated signaling pathways are minimally effective. Therefore, better understanding of crucial mechanisms underlying GBM is needed for developing more effective targeted therapies.

Methods: Target genes controlled by HIF1a in GBM were identified by analysis of TCGA database and by RNAsequencing of GBM cells with HIF1a knockout by sgRNA-Cas9 method. Functional roles of HIF1a, PDGFs and PDGF Rs were elucidated by loss- or gain-of-function assays or chemical inhibitors, and compared in response to oxygen tension. Pharmacological efficacy and gene expression in mice with intracranial xenografts of primary GBM were analyzed by bioluminescence imaging and immunofluorescence.

Results: HIF1a binds the PDGFD proximal promoter and PDGFRA intron enhancers in GBM cells under normoxia or mild-hypoxia to induce their expression and maintain constitutive activation of AKT signaling, which in turn increases HIF1a protein level and activity. Paradoxically, severe hypoxia abrogates PDGFRa expression despite enhancing HIF1a accumulation and corresponding PDGF-D expression. Knockout of HIFIA, PDGFD or PDGFRA in U251 cells inhibits cell growth and invasion in vitro and eradicates tumor growth in vivo. HIF1A knockdown in primary GBM extends survival of xenograft mice, whereas PDGFD overexpression in GL261 shortens survival. HIF1a inhibitor Echinomycin induces GBM cell apoptosis and effectively inhibits growth of GBM in vivo by simultaneously targeting HIF1a-PDGFD/PDGFRa-AKT feedforward pathway.
\end{abstract}

Conclusions: HIF1a orchestrates expression of PDGF-D and PDGFRa for constitutive activation of AKT pathway and is crucial for GBM malignancy. Therefore, therapies targeting HIF1a should provide an effective treatment for GBM.

Keywords: HIF1a, PDGFRa, PDGF-D, Glioblastoma, Echinomycin

\footnotetext{
* Correspondence: yanliu@ihv.umaryland.edu; yang|@oncoc4.com

${ }^{\dagger}$ Gong Peng and Yin Wang co-first authors.

2Division of Immunotherapy, Department of Surgery and Comprehensive

Cancer Center, Institute of Human Virology, University of Maryland School of Medicine, Baltimore, USA

Full list of author information is available at the end of the article
}

(c) The Author(s). 2021 Open Access This article is licensed under a Creative Commons Attribution 4.0 International License, which permits use, sharing, adaptation, distribution and reproduction in any medium or format, as long as you give appropriate credit to the original author(s) and the source, provide a link to the Creative Commons licence, and indicate if changes were made. The images or other third party material in this article are included in the article's Creative Commons licence, unless indicated otherwise in a credit line to the material. If material is not included in the article's Creative Commons licence and your intended use is not permitted by statutory regulation or exceeds the permitted use, you will need to obtain permission directly from the copyright holder. To view a copy of this licence, visit http://creativecommons.org/licenses/by/4.0/ The Creative Commons Public Domain Dedication waiver (http://creativecommons.org/publicdomain/zero/1.0/) applies to the data made available in this article, unless otherwise stated in a credit line to the data. 


\section{Background}

Glioblastoma multiforme (GBM) is the most common primary aggressive brain tumor, causing death within two years after diagnosis despite current therapies [1]. Malignant GBM is referred to as grade IV astrocytic glioma, based on WHO classification of four histology grades comprised of pilocytic, diffuse, anaplastic astrocytomas and glioblastoma, and incorporated with molecular genetic features for diagnosis [2-4]. Based on gene mutations and molecular profiling, GBM is divided into four subtypes including proneural, neural, classical and mesenchymal GBMs [4,5]. Most proneural GBM, the most resistant subtype, have mutations in TP53 in conjunction with overexpression of PDGFR $\alpha$ [5]. Integrative genetic analysis has demonstrated that $88 \%$ of GBM is caused by constitutive activation of the receptor tyrosine kinase (RTK)/RAS/PI3K signaling pathways and defective $R B$ and/or ARF-p53 signaling pathways [6-8]. Genes encoding epithelial growth factor receptor (EGFR) and PDGFR $\alpha$ were altered by amplification, rearrangements and mutations, resulting in increased receptor tyrosine phosphorylation in GBM [9]. In adult GBM, EGFR amplification is the most frequent alteration $(45-57 \%$ of cases), while PDGFRA amplification is the second most frequent (10 to $20 \%$ cases). The incidence of PDGFRA amplification increases to $23 \%$ in pediatric GBM [10] and $30 \%$ in high-grade pediatric gliomas [9, 11, 12]. Other genetic lesions, including PDGFRA activating mutations and gene rearrangements, as well as EGFR amplification, often occur concurrently in tumors with $P D G F$ $R A$ amplification [11-15]. However, overexpression of PDGFRA was detected in majority of proneural subtype GBM, which was substantially more frequent than PDGFRA genetic alterations [5]. Meanwhile, genetic alterations of components of the PDGFR $\alpha$-PI3K-AKT signaling pathway occur in up to $70 \%$ of GBM [16]. Moreover, co-overexpression and co-activation of PDGF $\mathrm{R} \alpha$ with EGFR often occur in GBM tumors without amplification of either gene [17-19] but with a typical feature of high angiogenesis such as the most common EGFRvIII mutant-overexpressing GBM [20, 21].

HIF $1 \alpha$ is stabilized under hypoxic conditions and responsible for directing tumor angiogenesis. Hypoxia inactivates the prolyl-hydroxylases in cytosol and the arginine hydroxylase factor inhibiting HIF $\alpha$ in nucleus, leading to the prevention of recognition and degradation of HIF $\alpha$ by the E3 ligase Von Hippel-Lindau, and to the inhibition of $\mathrm{HIF} \alpha$ transcriptional activity, respectively [22-24]. In contrast, we demonstrated an essential role of HIF $1 \alpha$ under normoxia in leukemia/lymphoma stem cells, which is efficiently targeted by echinomycin, an inhibitor of HIF1 $\alpha$ transcriptional activity $[25,26]$. Glioblastoma typically features three-layers including a necrotic core, intermediate/hypoxic layer, and a well- oxygenated and -vascularized, highly-proliferative outer layer comprising the invasive tumor frontier [27, 28]. HIF $2 \alpha$ is required for the growth of glioma stem cells at hypoxia [29]. Although HIF1 $\alpha$ is highly expressed in both glioma stem and bulk tumor cells [29], its role has not been thoroughly evaluated.

The family of PDGFs and PDGFRs is comprised of PDGF-A, B, C and D, and PDGFR $\alpha$ and $\beta$. Overexpression of PDGF-A, B, and C has demonstrated that PDGFPDGFR signaling plays an important role in both normal development and tumorigenesis of the central nervous system (CNS) [30, 31]. PDGFR $\alpha$ is expressed predominantly in glial progenitors and has a reduced expression in mature astrocytes [32]. In mice, PDGFR $\alpha$ overexpression, together with the loss of ARF, was reported to induce GBM via PDGFR $\alpha$-PI3K-AKT activation [33]. PDGFR $\beta$ is mostly restricted in the glioma-associated stroma, but can be induced in glioma cells by microglia to enhance the migration of glioma cells $[34,35]$. Its ligands, PDGF-B and PDGF-D, were both shown to be more potent mitogens for the growth and transformation of fibroblast cells than PDGF-A and PDGF-C [36, 37]. Overexpression of PDGF-B in glial progenitors of transgenic mice induced gliomas in a longer latency, and high-grade gliomas at a shorter latency once combined with Arf or Trp53 deficiency [38, 39]. However, the expression, function, and regulation of PDGF-D in CNS cells remains less known.

Here, we demonstrate that HIF1 $\alpha$ plays a critical role in favoring the growth of GBM cells via directly inducing the expression of both PDGF-D and PDGFR $\alpha$ for constitutive AKT activation, which primarily occurs at normoxia or mild-hypoxia. The induced PDGF-D is essential for GBM growth in vivo via an autocrine and/ or paracrine manner, to increase tumor invasion and angiogenesis in mouse models of GBM.

\section{Materials and methods \\ Mice, cells and reagents \\ Mice \\ Nod.Scid.Il2rgo (NSG) mice were purchased from the Jackson lab. Mice at 6-8 weeks were used for the intra- cranial implantation of glioblastoma cells and for the treatment. All experiments were performed using mycoplasma-free cells.}

\section{Cell lines and primary GBM cells}

The human GBM cell lines U251 and U87MG and mouse GBM line GL261 were obtained from the Cell Bank of Chinese Academy of Sciences (Shanghai, China). These GBM cell lines were cultured in high-glucose DMEM supplemented with 10\% FBS, $2 \mathrm{mM}$ glutamine and penicillin/streptomycin $(100 \mathrm{U} / \mathrm{mL}$, each), and maintained at $37^{\circ} \mathrm{C}, 5 \% \mathrm{CO} 2$ incubator. Unless stated 
otherwise in the figures or figure legends, GBM cells were cultured at normoxia ( $21 \%$ oxygen).

Primary LGG and GBM samples were obtained from surgical-resections of adult gliomas at the First Hospital of Jilin University between Jan 2013 and Jun 2014 (Supplemental Table 1). The Ethics Committee of the Jilin University approved and patient consent was provided for this study. Two primary GBM tissues obtained from surgical resections were immediately placed in RPMI 1640 medium. The tissues were chopped into a fine paste with scalpels and digested in $0.25 \%$ trypsin/EDTA solution containing $100 \mathrm{U} / \mathrm{mL}$ DNase I (Sigma-Aldrich) for $30 \mathrm{~min}$ at $37^{\circ} \mathrm{C}$ with $125 \mathrm{rpm}$ shaking, and terminated by adding 10\% FBS DMEM medium. Digested cells were pelleted by centrifugation, gently suspended with $1 \mathrm{~mL}$ of $1 \mathrm{x}$ lysing buffer solution (BD Bioscience) for a total of $2 \mathrm{~min}$, neutralized with $10 \mathrm{~mL}$ DMEM medium, passed through a $70 \mu \mathrm{m}$ filter, and pelleted by centrifugation. The isolated cells were cultured in NeuroCult basal medium containing $1 \mathrm{x}$ differentiation supplement (Stem Cell Technology), $40 \mathrm{ng} / \mathrm{mL}$ EGF (Invitrogen), $20 \mathrm{ng} / \mathrm{mL}$ b-FGF (Invitrogen), $1 \mathrm{mM}$ glutamine, and $1 \mathrm{x}$ antibiotics. The primary cells at less than three passages were used for in vitro assays and the freshly separated tumor cells from mice were used for in vivo assays and tumor implantation.

\section{Reagents}

Rabbit HIF1 $\alpha$ antibody (GTX127309, GeneTex), Phospho-Y754-PDGFRa (Ab5460, Abcam), PhosphoAKT(S473) and AKT, Phospho-ERK(T202/Y204) and ERK, Phospho-EGFR (Y1068) and EGFR, and PDGFR $\beta$ (28E1) all from Cell Signaling Technology; rabbit PDGF R $\alpha$ (C20, sc338), mouse monoclonal PDGFR $\alpha$ (C9, sc398,206 ) and p53 (DO-1, sc-126), and rabbit GAPDH (FL-335, sc-25,778) all from Santa Cruz, were purchased. Goat PDGF-D (AF-1159) antibody for human, PDGFDD ELISA kit (DDD00) and all PDGF growth factors were purchased from R\&D Systems. Mouse CD31 antibody (JC/70A, MA5-13188) and rabbit PDGF-D (402100) from Invitrogen, rabbit PDGF-B (28E1, AF0204) from affinity Biotech, beta-actin (AC-74) antibody and puromycin from Sigma, and the PDGFR inhibitor AG1296 and the EGFR inhibitor AG1478 from Cayman Chemical, were purchased.

\section{Plasmids}

The full-length coding cDNAs of HIF1A from human bone marrow cells and of PDGFRA and PDGFD, both from U251 cells, were cloned into a pcDNA vector and identified by DNA sequencing. The triple HIF1A mutant form (P402A/P564A/N802A, named as HIF1 $\alpha-\mathrm{PPN})$ was made by site-directed mutagenesis using HIF1A as template and a kit from Clontech. The PDGFD-dCUB construct was made by deletion of the CUB domain of PDGFD using Platinum SuperFiII DNA polymerase (Invitrogen) and ligated with T4 ligase (Promega).

\section{Cas9/CRISPR gene knockout in glioblastoma cells}

Design of small Cas9-guided RNA (sgRNA) sequence was based on the website tool of Zhang's lab (http:// crispr.mit.edu/). Knockout of HIF1A or PDGFD or PDGFRA genes was performed in U251 or U87MG cells by transfecting the sgRNA-expressing plasmid of HIF1A or PDGFD or PDGFRA or control scrambled sg (Sr-sg). The plasmid is constructed in a Lenti-Crisp-V2 vector (addgene, Cambridge, MA) and expresses both Cas9 protein and sgRNA of the DNA sequence of HIF1A (5ccatcagctatttgcgtgtg-3) or PDGFD (5-ctttgcgcaacgccaacctc-3) or PDGFRA (5-cggcctttttgtgacggtct-3) or Srsg (5-gagacggttgtaaacgtctc-3). The U251 or U87MG cells cultured in a $100 \mathrm{~mm}$ dish at about $80 \%$ confluence were transfected with the individual sgRNA-Cas9 plasmid using lipofectamine 3000 reagent. Two days after transfection, the cells were passaged at 1:4 ratios into $100 \mathrm{~mm}$ culture dishes and 2 days later were treated with $2 \mu \mathrm{g} / \mathrm{ml}$ puromycin. About 96 puromycin-resistant clones were picked up for each gene knockout. Positive clones were selected by immunofluorescent staining and Western blot before directly sequencing of their DNA PCR products to confirm their knockout. The Sr-sgRNAtransfected cells were selected with puromycin and drug-resistant cell pool was used as knockout control, hereafter referred to as wild type (WT).

\section{Gene knockdown by shRNA lentivirus}

Overnight culture of freshly isolated GBM cells from NSG recipients were transduced with high-titer lentiviral mixture of HIF1 $\alpha$-sh 1 and HIF1 $\alpha$-sh 2 or with scrambled-sh (Sr-sh) controls for $30 \mathrm{~h}$ before checking the expression of GFP-reporter under microscope and the $1 \times 10^{5}$ transduced cells/mouse were injected intracranially into NSG mice. The two lentiviral shRNA plasmids were constructed by cloning DNA oligo sequences of HIF- $1 \alpha$ (sh1, 5-gcgaagtaaagaatctgaag; sh2, 5-gaaactcaagcaactgtca) or Srsh (sh1, 5-gtgctatcacctcactgaa; sh2,5-gacatctcgacgtgcagcaa) into a lentiviral shRNA vector with GFP as reporter [25].

\section{Promoter and chromatin immunoprecipitation (ChIP) assays \\ Promoter}

The proximal promoter regions of human PDGFD and PDGFRA were PCR amplified from genomic DNA of healthy human PBMCs. Primers used for PCR were as follows: PDGFD, forward (5'-gaaggcaagtgagcacagtgttct-3') and reverse ( $5^{\prime}$-agctctccccaaacttcctgcat-3'); PDGFRA forward $\left(5^{\prime}\right.$-attgtcatattggactcaacagtt- $\left.3^{\prime}\right)$ and reverse $\left(5^{\prime}\right.$ accttctcctccgatgttattc- $\left.3^{\prime}\right)$. To establish promoter reporters, 
the PCR fragment was cloned into lentiviral vector upstream of the GFP reporter to allow promoter-driven expression of GFP. For the PDGFRA promoter construct, DNA oligos of the PDGFRA enhancers (located within the first intron containing consensus HRE sites) were synthesized and inserted downstream of the PDGFRA proximal promoter. The DNA sequences of the enhancers are as follows: E1 (5' -ctacccacggccgtgcggctctcgtgcccatag-3'), E2 (5'-caacccgtggacgcacgtccttggaccaacactg- $\left.3^{\prime}\right)$.

\section{ChIP assay}

U251 cells were starved of serum for $8 \mathrm{~h}$ and re-flashed with medium containing $10 \%$ FBS for $2 \mathrm{~h}$ before $1 \%$ formalin fixation. The rabbit HIF1 $\alpha$ antibody was used for immunoprecipitation of sonicated SDS lysate diluted at 1:10 ratio with dilution buffer. The following steps were performed according to the guidelines for ChIP Assay Kit (17-295, Millipore). Control IgG was used as a parallel control. HIF1 $\alpha$-bound regions in the promoters of PDGFD and PDGFRA pulled down by ChIP were amplified by PCR using primer pairs as follows: PDGFD, forward (5'-aggcaagtgagcacagtgttctg- $\left.3^{\prime}\right)$ and reverse (5'taccagagagtattggacacc- $\left.3^{\prime}\right)$; PDGFRA, proximal promotor P1 forward ( $5^{\prime}$-cctgacagctatttacttaga- $\left.3^{\prime}\right)$ and reverse (5'cttctcctccgatgttattc- $\left.3^{\prime}\right)$; enhancer E1 forward (5'ctggtctcgaactcctgacct- $\left.3^{\prime}\right)$ and reverse (5'-aggggtttagggttacagga-3'); enhancer E2 forward (5'-caactgaggtcaccacgaaag-3') and reverse ( $5^{\prime}$-tcctaatggtctccgcgaag- $\left.3^{\prime}\right)$.

\section{Promoter activity}

HEK293T cells were plated onto a 24 -well plate $\left(2 \times 10^{5}\right.$ cells per well) $12 \mathrm{~h}$ before transfection. The cells were transiently transfected with various promoter plasmids and with/without HIF1 $\alpha$-PPN (P402A/P564A/N803A mutant) plasmid (total DNA $500 \mathrm{ng} /$ per well) using lipofectamine 3000. Twenty-four or $36 \mathrm{~h}$ after transfection, the GFP signals of the cells were photographed under fluorescence microscope and the mean fluorescence intensity (MFI) of the cells was determined by flow cytometry. Red fluorescent control plasmid was co-transfected with these promoter plasmids as internal control to read out transfection efficiency of each sample. One of quadruplicate wells was fixed with cold methanol to stain the Flag-tagged HIF1 $\alpha$-PPN to confirm its expression.

\section{In vivo tumor models}

GBM cells, $1 \times 10^{5}$ in $3 \mu$ DMEM medium, were stereotactically injected into the cerebral cortex of each anesthetized recipient NSG (for primary GBM) or C57BL/6 (for GL261) mouse at a depth of $2 \mathrm{~mm}$. Mice were randomly grouped ( $n=5-6 /$ group), and treated with $250 \mu \mathrm{g} / \mathrm{kg}$ Liposomal Echinomycin (LEM) or vehicle via tail vein injection every other day for a total of 4 injections, beginning on day 10 (xenograft mice) or day 7
(GL261). Survival was determined based on the removal criteria to estimate the Kaplan-Meier survival curves. The WT and KO U251 cells were transduced with lentiviruses of GFP-Luciferase reporter and the sorted cultured GFP-positive cells were injected in the cerebral cortex of NSG mice as with the GBM primary cells.

\section{Clinical samples for gene expression analysis}

We analyzed the gene transcript expression of HIF1 $\alpha$ and its targets, PDGFs and PDGFRs in GBM samples $(N=174)$ versus low-grade glioma (LGG) samples $(N=$ 529) from TCGA (The Cancer Genome Atlas). The Mann-Whitney test was used to determine statistical significance.

\section{Results}

\section{High HIF1a activity and PDGFs/PDGFRs expression in} GBM

To identify key molecules or pathways in driving GBM malignancy, we analyzed 174 GBM and 529 low-grade glioma (LGG) patient samples from the Cancer Genome Atlas (TCGA). This analysis revealed significantly higher expression of HIF1 $\alpha$ and its targets in GBM vs LGG, particularly those involved in glycolysis (PDK1, PGK1, HK2, SLC2A1/GLUT1, SLC16A3/MCT4, LDHA), angiogenesis (VEGF-A), and tyrosine receptor signaling pathway (IGFBP2) (Fig. 1A). Growth factors PDGFA, PDGFB and $P D G F D$ were also more highly expressed in GBM (Fig. 1A). Interestingly, expression of PDGFRA, a major growth factor receptor in glioma cells, was significantly reduced in GBM, whereas PDGFRB was increased (Fig. 1A). To identify which pathways may be controlled by HIF1 $\alpha$ in GBM, and to validate our findings from TCGA, we performed exome RNA-sequencing (RNASeq) on U251 cells after using Cas9-guided RNA (sgRNA) method to knockout HIF1 $\alpha$. Analysis of growth factors, receptors, and substrates in AKT signaling pathway, and HIF1 $\alpha$ target genes involved in glycolysis, de novo lipogenesis, and angiogenesis, revealed that $P D G F$ D, PDGFRA, IGFBP2, PDK1,3, SLC16A1,3/MCT1,4, and lipogenesis genes $S C D$ and $F A S N$ were all consistently downregulated in U251 cells following genetic ablation of HIF1 $\alpha$, in comparison to scrambled sgRNA control (Fig. 1B,C, Table S2, S3). These data indicate that the expression of PDGFRA and PDGFD in GBM cells depends more on HIF1 $\alpha$ compared with the expression of other receptors and growth factors, such as PDGFB. Moreover, surgically resected primary LGG $(n=3)$ and GBM $(n=$ 6) tissue samples were compared for HIF1 $\alpha$, PDGFR $\alpha$ and PDGF-D levels by Western blot. The data revealed high protein levels of HIF1 $\alpha(5 / 6)$, PDGFR $\alpha(4 / 6)$ and PDGF-D (5/6) in most of the 6 GBM cases (Fig. 1D). These results suggest a positive relationship between HIF $1 \alpha$ and PDGF-D and PDGFR $\alpha$ in GBM. 


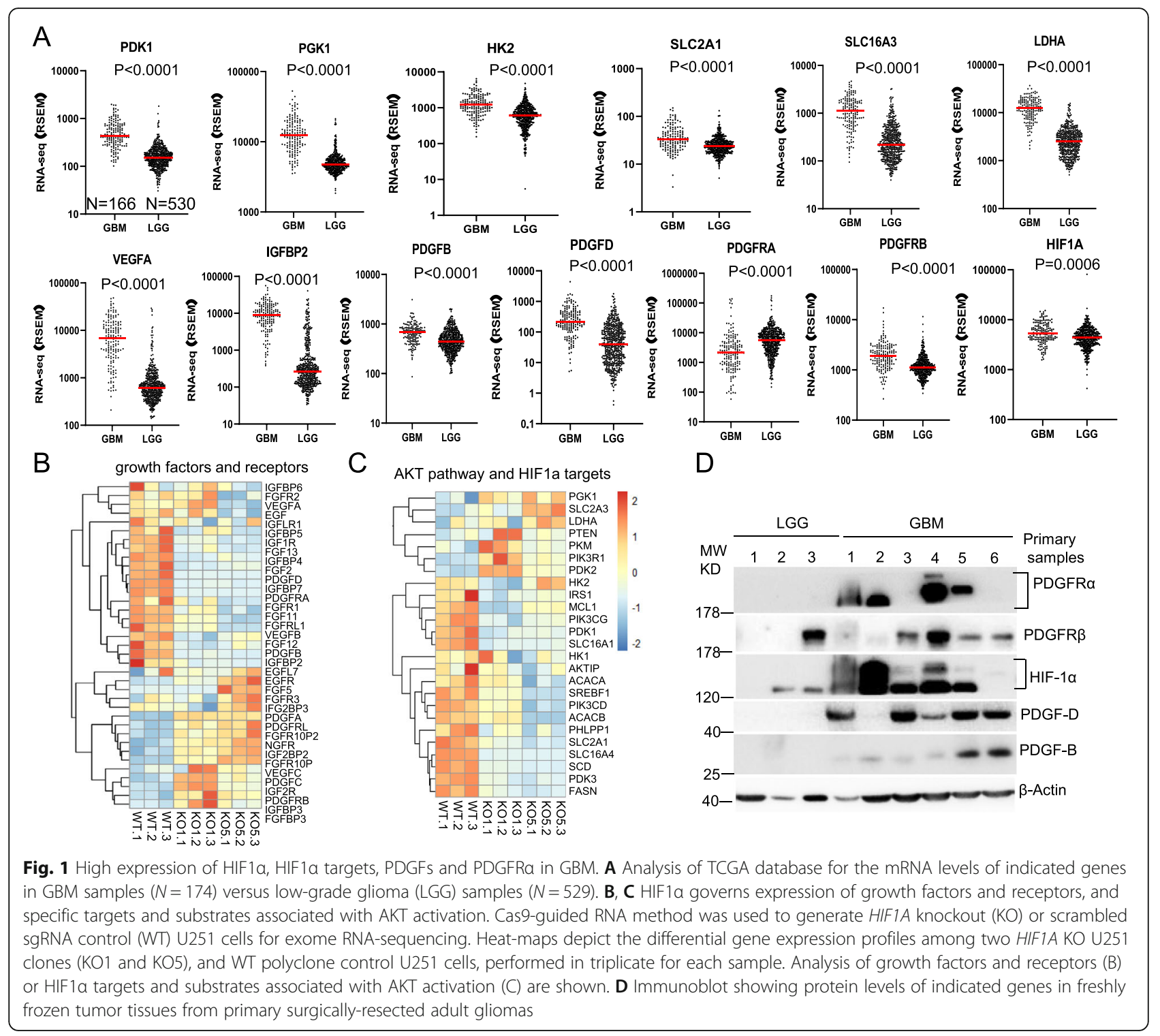

\section{HIF1a is required for the growth and invasion of GBM} cells

Whether HIF1 $\alpha$ plays a critical role in GBM growth remains undefined, although HIF1 $\alpha$ knockdown was shown to inhibit growth and invasion of glioma cell lines in vitro [40]. We used sgRNA to target HIF1A in GBM cell lines, U251 and U87MG. The two clones with HIF1A knockout (KO) in U251 cells were confirmed by Western blot and by directly sequencing their PCR products (Fig. 2A and Fig. S1). Both HIF1A KO U251 clones exhibited reduced growth (Fig. 2B) and invasion (Fig. 2C,D). The size of tumor spheres was also reduced (Fig. 2E). In addition, HIF1A KO U251 cells cultured at low cell density exhibited increased levels of apoptotic proteins, cleaved caspase 3 (cCasp3) and cleaved PARP (bottom bands). The trend was more pronounced when the cells were treated with the hypoxia mimetic $\mathrm{CoCl}_{2}$. More strikingly, HIF1A KO U251 clones were unable to either form tumors or cause mortality in xenograft recipient NSG mice (Fig. 2G, H). Similarly, the HIF1A mutated clone of U87MG cells also exhibited greatly reduced colony formation and delayed tumor growth in xenograft recipients (Fig. S2B, C).

To test if HIF1A is critical for tumor growth in primary GBM cells, we performed similar experiments in xenograft mice using Glio-1 and Glio-2 cells. To maintain the heterogeneity of primary GBM, we used hightiter lentiviral HIF1A silencers to infect the cells prior to intracranial transplantation. As shown in Fig. S3A, infection efficiency was similar in HIF1A shRNA- or scrambled shRNA - infected cells, based on expression of the GFP reporter. Co-transfection of HEK293FT cells with 


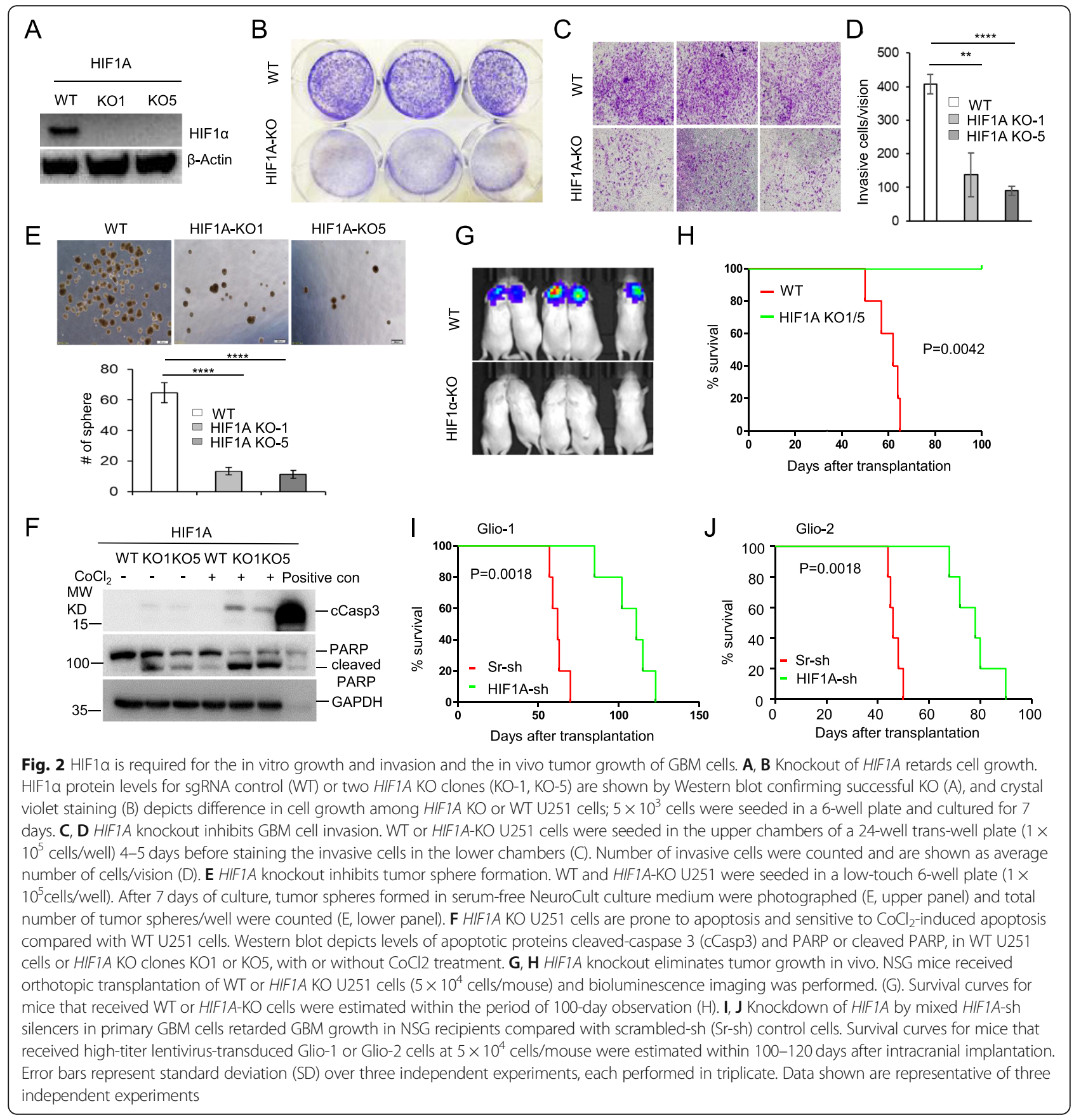

$H I F 1 A$-sh-GFP and HIF1 $\alpha$-P2A-RFP plasmids validated the successful shRNA knockdown of HIF1A mRNA by the expression of RFP and GFP reporters, as the HIF $1 \alpha-$ P2A-RFP plasmid allows for HIF1 $\alpha$ and RFP to be expressed as a single mRNA transcript which is then translated as two proteins, separated by the self-cleaving peptide P2A (Fig. S3B). As shown in Fig. 2I and J, silencing HIF1A in the Glio-1 or Glio-2 primary cells also restrained tumor growth and significantly extended survival of recipient mice compared to scrambled shRNA control cells (Sr-sh) (Fig. 2 I, J). Taken together, these data indicate that HIF1 $\alpha$ plays a critical role in the growth and in vitro invasion of GBM cells.

\section{HIF1a regulates expression of PDGFRA and PDGFD in GBM cells}

As oxygen availability is unevenly distributed throughout GBM tumors, we examined the impact of differential oxygenation on protein levels of HIF1 $\alpha$, PDGFR $\alpha$, PDGF-D, and phospho-AKT in WT or HIF1A-KO U251 cells exposed to a range of oxygen tensions. As shown in Fig. 3A, in wild type cells, mild hypoxia $\left(5 \% \mathrm{O}_{2}, 8 \mathrm{~h}\right)$ 


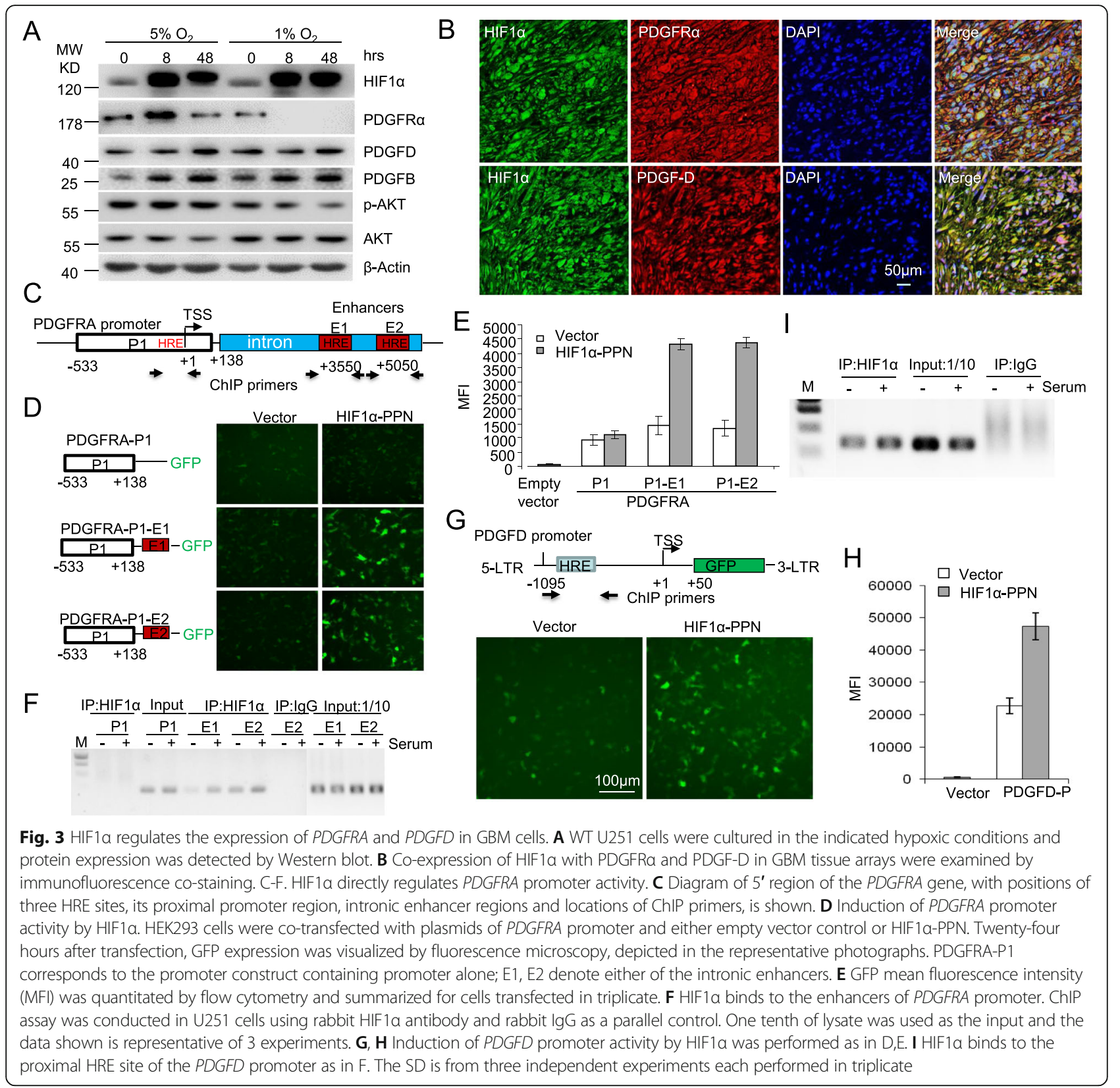

increased protein levels of both HIF1 $\alpha$ and PDGFR $\alpha$ with minimal effect on PDGF-D and PDGF-B, whereas moderate $\left(5 \% \mathrm{O}_{2}, 48 \mathrm{~h}\right)$ or severe $\left(1 \% \mathrm{O}_{2}, 48 \mathrm{~h}\right)$ hypoxia increased PDGF-D and PDGF-B protein levels but dramatically reduced that of PDGFR $\alpha$ (Fig. 3A, S3C). However, neither mild nor moderate hypoxia increased the activation of AKT and, like PDGFR $\alpha$, severe hypoxia actually reduced AKT activation despite maintaining the accumulation of HIF1 $\alpha$ (Fig. 3A). HIF1A knockout dramatically reduced the expression of both PDGFR $\alpha$ and PDGF-D, moderately reduced PDGF-B, but increased PDGFR $\beta$ at normoxia (Fig. S3C). Combined with the growth reduction and hypoxia-induced apoptosis in
HIF1A-KO cells (Fig. 2), these results indicate that HIF1 $\alpha$ favors GBM cell growth in normoxic and mild to moderate hypoxic conditions in which the growth factors and the receptor PDGFR $\alpha$ and the AKT activation are all maintained persistently.

To ascertain the correlation between HIF1 $\alpha$ and PDGFR $\alpha$, we tested expression of HIF $1 \alpha$ and PDGFR $\alpha$ among 35 cases of GBM tissues. We observed high expression of both proteins in 21/35 GBM cases, depicted in the representative images (Fig. 3B, upper row), and intensity of HIF- $1 \alpha$ staining was highly correlated with that of PDGFR $\alpha$, with rare instances of single-positive staining (Fig. S4C). In addition to GBM, co-expression 


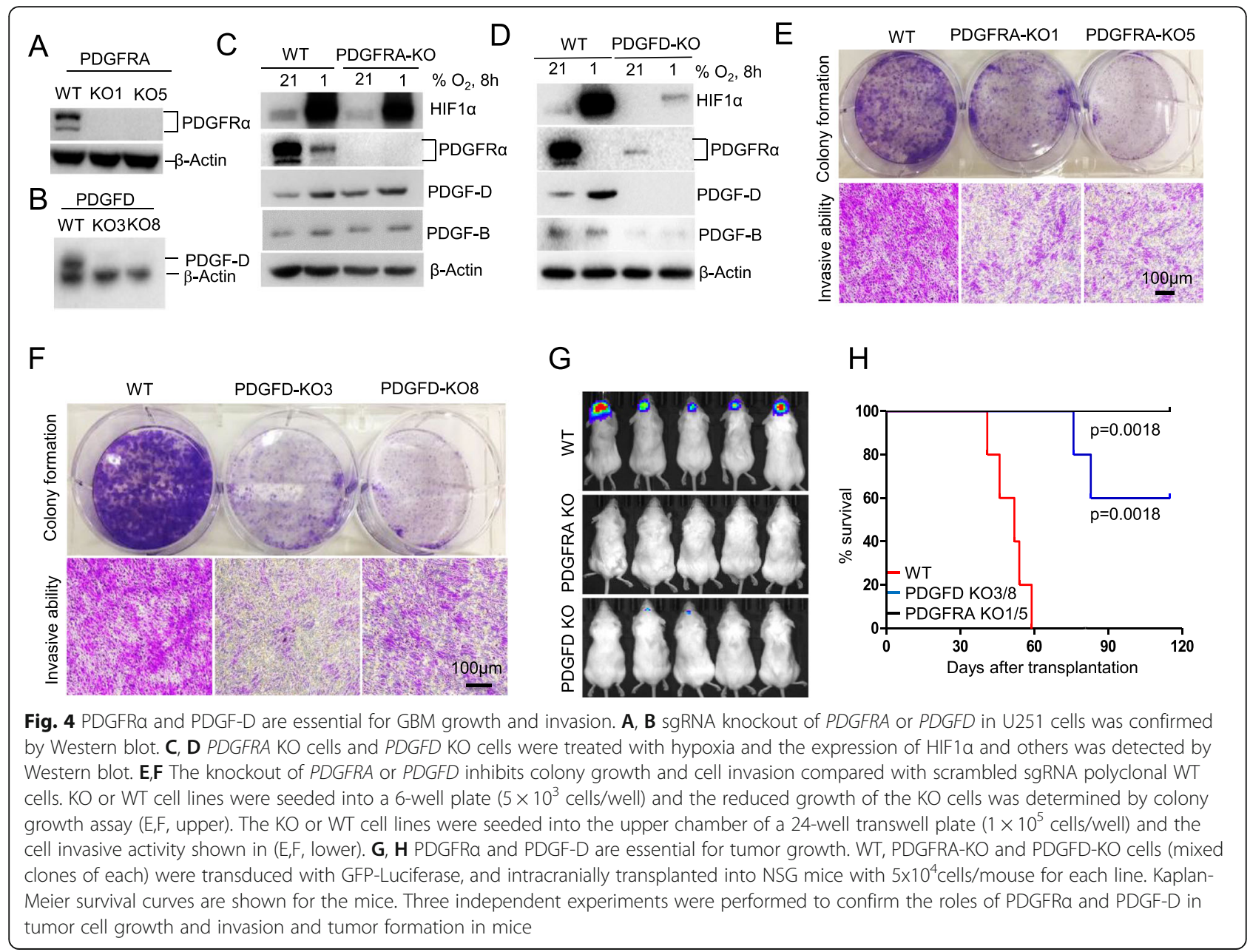

of HIF1 $\alpha$ and PDGFR $\alpha$ proteins was also observed in other types of gliomas, but not in medulloblastoma or adjacent normal brain tissues (ANB) (Fig. S4 A,B). Similarly, we observed a correlation between HIF1 $\alpha$ and PDGF-D expression with double positive stains observed in 23 of 38 cases of a GBM tissue microarray (Fig. S4C), and representative double-positive staining shown in Fig. $3 \mathrm{~B}$, bottom row.

To see if HIF1 $\alpha$ directly regulates the expression of PDGFRA and PDGFD in GBM, we first identified a putative hypoxia-response element (HRE) in the PDGFRA proximal promoter, and 2 HREs within intron 1 of the PDGFRA gene (Fig. 3C). We cloned the PDGFRA proximal promoter, with or without its intronic HREs, into a GFP-reporting vector and cotransfected the constructs with mutant HIF1 $\alpha$-PPN (a P402A/P564A/N803A mutant resistant to degradation under normoxia) into HEK293 cells. As shown in Fig. 3D and E, HIF1 $\alpha$ did not induce the proximal promoter activity of PDGFRA (PDGFRA-P1). Adding either intronic HRE to the basic promoter upstream of the GFP reporter (PDGFRA-P1E1 and PDGFRA-P1-E2, respectively) resulted in the activation of the PDGFRA promoters (Fig. 3D,E). The PDGFRA-P1-E1 promoter activity was also activated by hypoxia mimetic $\mathrm{CoCl}_{2}$ in concentrations ranging from 50 to $250 \mu \mathrm{g} / \mathrm{ml}$ (Fig. S3D). Chromatin immunoprecipitation (ChIP) in WT U251 cells with or without 8-h serum-starvation revealed that endogenous HIF1 $\alpha$ can bind to the regions encompassing each of the enhancers, but not to the HRE region located in the proximal basic promoter of PDGFRA under normoxic conditions (Fig. $3 \mathrm{~F})$. These results demonstrated that HIF $1 \alpha$ regulates the expression of PDGFRA through binding to the PDGFRA enhancers rather than its basic promotor.

HIF1 $\alpha$ also activated the proximal promoter activity of PDGFD in HEK293 cells co-transfected with plasmids of stable HIF1 $\alpha$-PPN and the PDGFD promoter (PDGFDP-GFP) (Fig. 3G). Compared to empty vector, HIF1 $\alpha$ enhanced the promoter activity more than 2-fold, as determined by flow-cytometry (Fig. $3 \mathrm{H}$ ). $\mathrm{CoCl}_{2}$ also activated the PDGFD promoter activity at concentrations ranging from 100 to $500 \mu \mathrm{g} / \mathrm{ml}$ (Fig. S3D). ChIP revealed endogenous HIF $1 \alpha$ bound to the proximal promoter region of PDGFD in U251 cells, which was also modestly 
increased by serum stimulation (Fig. 4I). No specific PCR product could be detected in control IgG ChIP assay, which confirmed the specificity of HIF $1 \alpha$ binding to PDGFD (Fig. 4I). Therefore, HIF1 $\alpha$ directly regulated PDGF-D expression in GBM.

\section{PDGFRa and PDGF-D are required for invasion and growth of GBM cells}

To test if HIF1 $\alpha$-regulated PDGF-D and PDGFR $\alpha$ are essential for GBM growth and invasion, we generated PDGFRA KO or PDGFD KO U251 cells by Crispr-Cas9 sgRNA editing method (Fig. 4A,B). Knockout of PDGF RA minimally affected HIF1 $\alpha$, PDGF-D and PDGF-B levels, at either normoxic or hypoxic conditions (Fig. 4 C), whereas knockout of $P D G F D$ dramatically reduced protein levels of HIF1 $\alpha$, PDGFR $\alpha$ and PDGF-B regardless of oxygen levels (Fig. 4D). Knockout of PDGFRA or PDGFD dramatically reduced growth and invasion of U251 cells in vitro when cells were seeded at low cell density (Fig. 4E, F). More importantly, these PDGFRA KO lines did not grow or cause mortality in NSG recipient mice throughout the observation period of 120 days (Fig. 4G, H). Mice that received PDGFD KO lines had significantly longer survival than mice engrafted with PDGFD WT cells (Fig. 4H). These results demonstrated that HIF1 $\alpha$ controls GBM growth mainly through upregulating the expression of PDGFR $\alpha$ and PDGF-D.

\section{HIF1a-PDGFD-PDGFRa pathway controls constitutive activation of AKT, leading to GBM cell growth and invasion}

PDGF-D was reported to bind to and activate PDGFR $\beta /$ $\beta$ homodimer and PDGFR $\alpha / \beta$ heterodimer in cells expressing both receptors $[41,42]$. As PDGFR $\beta$ expression was much lower in U251 cells than PDGFR $\alpha$ expression, we compared PDGF-D to other PDGF family members for their ability to activate PDGFR $\alpha$, and if so, whether such interactions result in the HIF $1 \alpha$ accumulation in normoxia. Stimulating U251 cells with recombinant PDGF-A, PDGF-B or PDGF-D induced phosphorylation of PDGFR $\alpha$ to a comparable extent, which was blocked by the PDGFR-specific tyrosine kinase inhibitor AG1296 (Fig. 5A), indicating PDGFR $\alpha$ acts as their receptor. Although the transactivation EGFR by PDGF-B was reported in fibroblasts [43], none of these PDGFs activated the phosphorylation of EGFR in U251 cells (Fig. 5A). The activation of PDGF to PDGFR $\alpha$ relayed signals to its down-stream pathway activation of both AKT and ERK, as the PDGFR inhibitor blocked their phosphorylation completely. The EGFR inhibitor AG1478 at $0.5 \mu \mathrm{M}$ concentration slightly inhibited the PDGFR $\alpha$ activation, as well as the activation of AKT and ERK induced by PDGF-D, whereas it completely blocked EGF-induced EGFR signaling cascades (Fig. 5A). The PDGFD-PDGF
R $\alpha$-AKT signaling cascade required HIF1 $\alpha$ for its constitutive activation because knockout of HIF1 $\alpha$ abolished the expression of both the ligand and receptor, and then the phosphorylation of AKT (Fig. 5B). This pathway activation is also required for HIF1 $\alpha$ accumulation in normoxia (Fig. 5B) because knockout of either PDGFD or PDGFRA abolished or reduced HIF1 $\alpha$ protein levels. Compared to AKT activation, transfection of PDGFRA to HIF1A KO U251 cells not only moderately increased AKT activation and cells growth, but also greatly enhanced the cell invasive ability in vitro (Fig. $5 \mathrm{C}, \mathrm{E}$ ). Overexpression of HIF1 $\alpha$ in HIF1A KO U251 cells completely restored the PDGFR $\alpha$ expression, AKT activation, and thus the colony growth and cell invasion in vitro (Fig. 6 D, E).

It is worth noting that ERK activation either in the absence of exogenous PDGF or in the presence of exogenous PDGF-D was moderately affected by ablation of $H I F 1 A$, although its activation by PDGF-A was dramatically affected by the HIF1A ablation (Fig. 5B). Since ERK activation is moderately affected by deletion of $P D G F R a$, and since PDGFR $\beta$ levels increased in the HIF1A knockout cells (Fig. S3C), the basal and PDGF-Dinduced activation of ERK may relate to PDGF-D interaction with PDGFR $\beta$ or other receptors that are independent of HIF1 $\alpha$ and PDGFR $\alpha$. Nevertheless, ERK activation by PDGFR $\beta$ signaling pathway cannot compensate the loss of HIF1 $\alpha$-PDGFD-PDGFR $\alpha$-AKT network for GBM tumor growth because knockout of either HIF1A or PDGFD or PDGFRA in U251 cells eradicated the tumor growth (Fig. 2G, H and Fig. 4G, H). As HIF1A knockout also abolished PDGF-D release (Fig. S5A), and PDGFD knockout largely reduced HIF1 $\alpha$ protein levels, their reciprocal regulation is both autocrine and feedforward.

\section{Echinomycin inhibits HIF1a-PDGFD-PDGFRa-AKT signaling and induces apoptosis of GBM cells}

Having established the novel feedforward mechanism of HIF1 $\alpha$-PDGFR-AKT pathway, we tested the effect of HIF1 $\alpha$ inhibitor Echinomycin in regulating this new pathway. Echinomycin inhibited PDGFR $\alpha$ expression and AKT activation in a dose-dependent manner under normoxic or mild hypoxic conditions (Fig. 6A). The inhibition was also time-dependent, as shown in Fig. 6B. We observed a similar dose-response when echinomycin was used to treat primary Glio-1 cells (Fig. 6C). Figures $6 \mathrm{D}$ and $\mathrm{E}$ showed that echinomycin also inhibited PDGF-D secretion in a dose-dependent manner from U251 cells. Correspondingly, Echinomycin induced apoptosis of U251 cells in a dose-dependent manner (Fig. 6F and S5B), although it had minimal effects on the viability of HIF1A $\mathrm{KO}$ cells at low doses when compared with WT cells, confirming its on-target effect (Fig. S5C). 


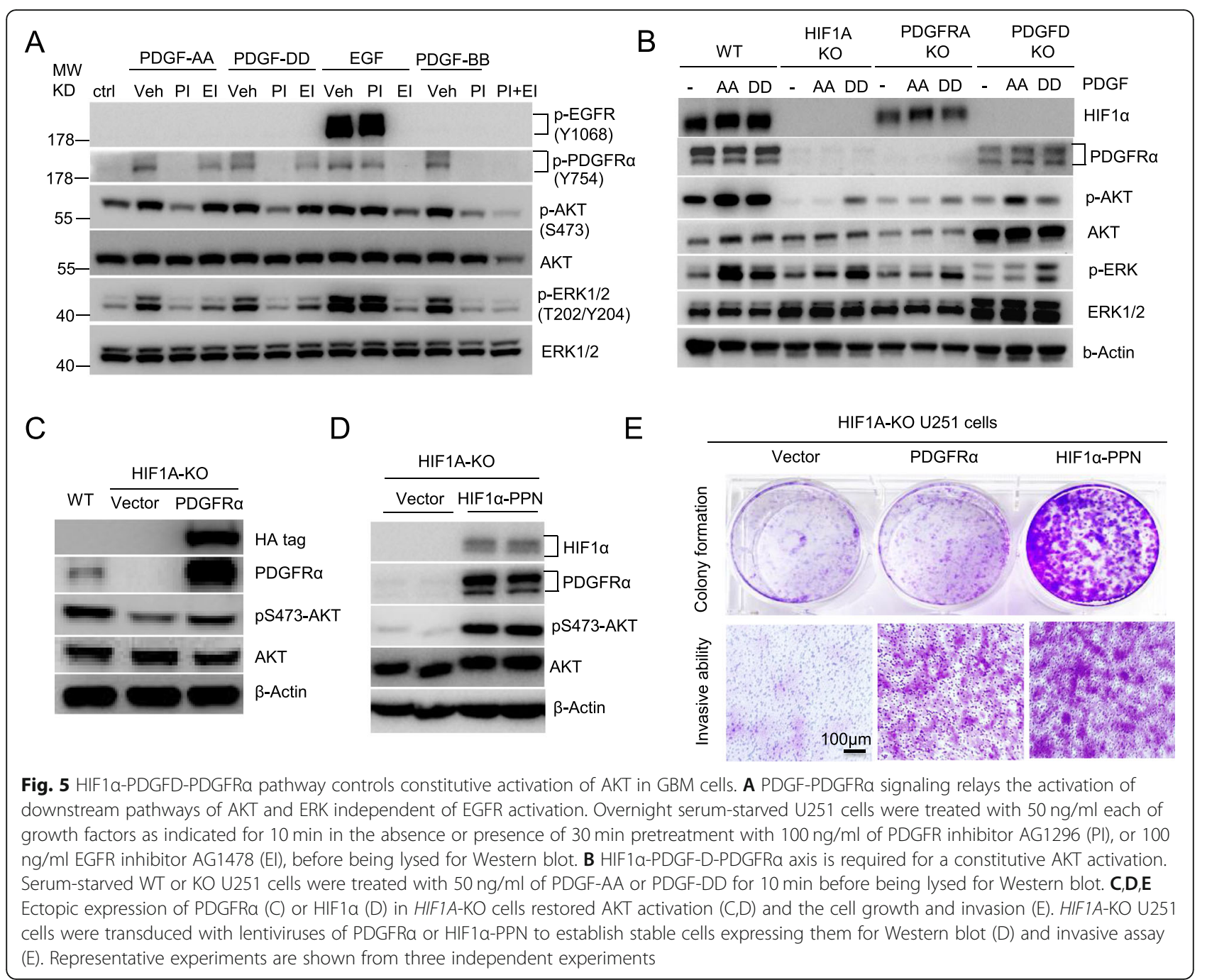

Similar to HIF1A KO cells, the PDGFRA KO cells also exhibited resistance to Echinomycin treatment (Fig. S5D), which suggests that the two proteins work on the same pathway for cell viability.

Targeting HIF1a by liposomal echinomycin inhibits tumor growth and prolongs survival of GBM-xenografted NSG mice

To test the impact of pharmacologically targeting the HIF1 $\alpha$ PDGFD-PDGFR $\alpha$ axis in GBM in vivo, we took advantage of an improved formulation of Echinomycin which we developed recently using liposomes (LEM) to treat solid tumors $[44,45]$. LEM prolonged survival in mice xenografted with primary Glio-1 or Glio-2 tumors by about 20 days (Fig. $6 \mathrm{G}, \mathrm{H})$. By sequencing the PCR products of the genomic DNA encompassing exons 2-9 of the TP53 gene, we found that Glio-1 cells were surprisingly contained the same $\mathrm{R} 273 \mathrm{H}$ hot-spot mutation as U251 cells, albeit heterozygous, whereas no TP53 mutation was observed in Glio-2 (Fig. S5E). However, regardless of TP53 mutation status, LEM conferred similar survival advantages to mice engrafted with either Glio-1 or Glio-2, indicating that HIF1 $\alpha$ and HIF1 $\alpha$ controlled PDGFD-PDGFR $\alpha$-AKT signaling contributes more to the sensitivity to Echinomycin treatment. Indeed, in comparison to vehicle controls, Echinomycin inhibited the Glio-1 tumor growth as seen in the reduced tumor size of representative sections (Fig. 6I, top), and the proliferation as judged by the reduced proliferative marker Ki67 in contrast to the increased apoptotic marker cleaved-caspase3 (Fig. 6I, bottom). Echinomycin also reduced immunofluorescent staining of HIF1 $\alpha$ and PDGF-D in GBM tissues (Fig. 6J). These results demonstrate that Echinomycin effectively targets the HIF1 $\alpha$-PDGF-D axis to inhibit GBM growth.

Overexpression of PDGF-D stimulates tumor growth and angiogenesis in immunocompetent mice, and renders sensitivity to echinomycin treatment

Unlike PDGF-B, which is expressed and released as an active homodimer, PDGF-D is expressed and released as an inactive homodimer that is activated by extracellular 


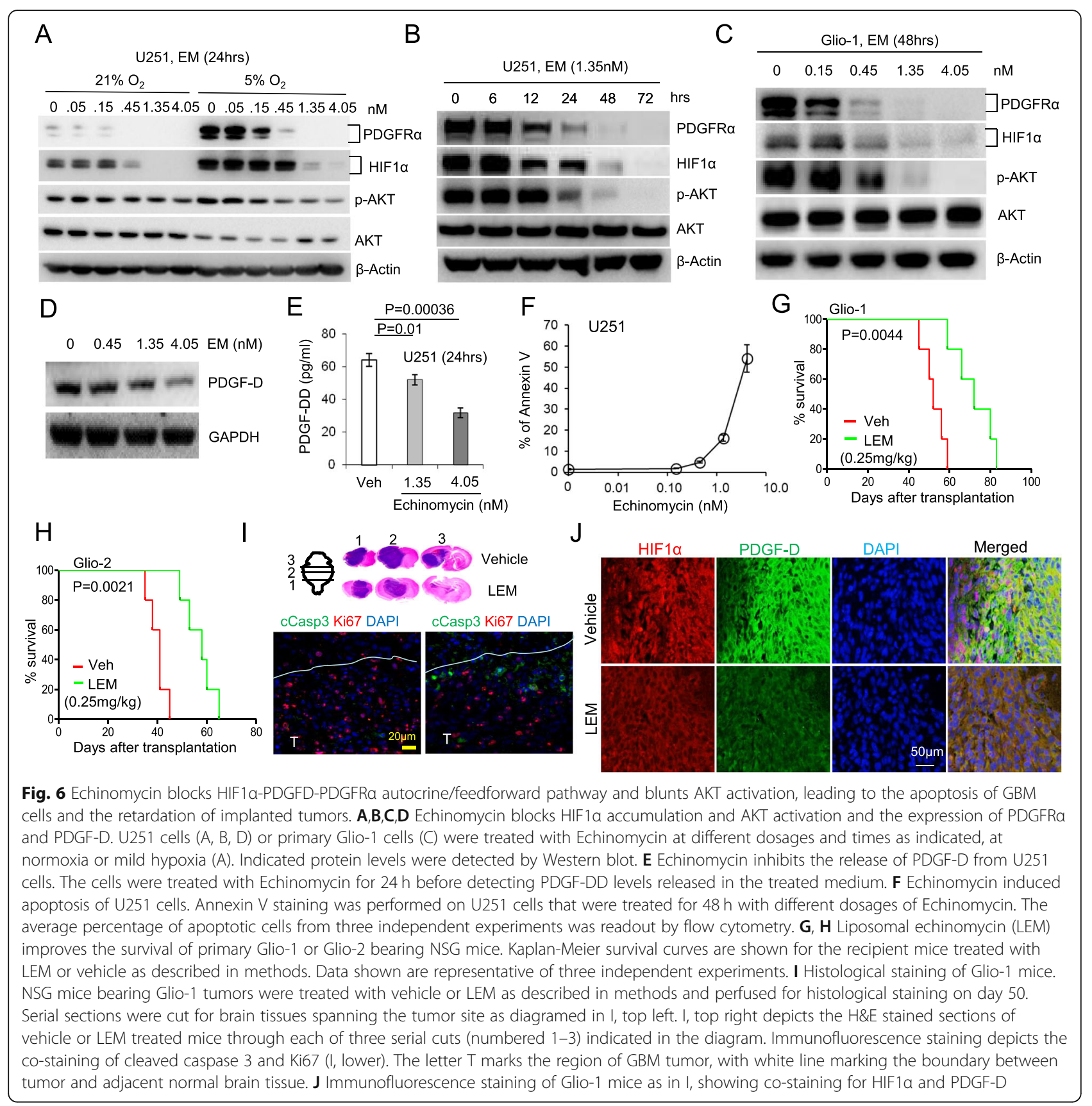

serine proteinases [46]. Thus, it has been unclear whether PDGF-D played a significant role in GBM pathogenesis. In murine GL261 GBM cells, ectopic overexpression of PDGF-D (Fig. 7A) significantly accelerated tumor growth and mortality of recipient mice (Fig. $7 \mathrm{~B}, \mathrm{C})$. Moreover, overexpression of the active form of PDGF-D (i.e. PDGFD-dCUB), resulting from deletion of the inhibitory CUB domain (Fig. 7A) [46] had an even more pronounced effect (Fig. 7B,C). The data indicates that GBM tumors are capable of proteolytically activating the potent growth factor PDGF-D. In response to a cycle of treatment (Fig. 7D), Echinomycin effectively neutralized the growth advantage of PDGFD-transduced GL261 tumors and conferred equivalent therapeutic effects for both transduced and un-transduced GL261 tumors (Fig. 7E,F). Immunofluorescence of PDGFR $\alpha$ and angiogenic marker CD31 in tumor tissues revealed an increase in GL261-PDGF-D vs GL261-vector tissues (Fig. 7G). LEM treatment of the GL261 brain tumor greatly reduced the expression of Pdgfd, Pdgfra and $I g f b p 2$, as detected by quantitative RT-PCR, compared to vehicle control tumors (Fig. S6).

Taken together, we demonstrate that HIF1 $\alpha$ is a crucial effector on the constitutive activation of AKT 


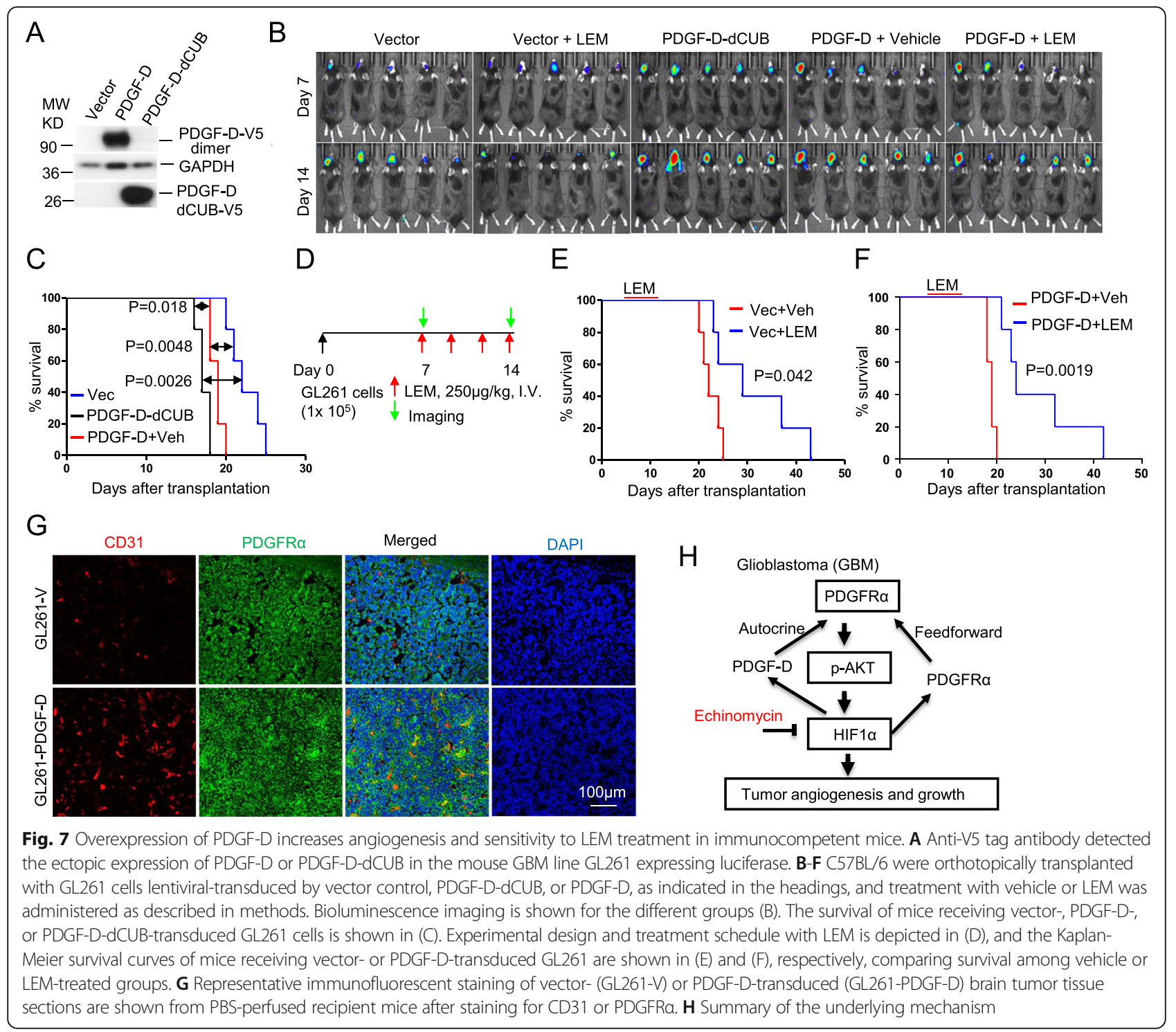

through controlling the expression of PDGF-D and PDGFR $\alpha$ in an autocrine and feedforward manner for GBM growth and malignancy, which could be therapeutically targeted by LEM (Fig. 7H).

\section{Discussion}

GBM is characterized by cellular heterogeneity, integrated oncogenic signaling pathways, intratumorallyintricate microenvironments, and distinct regions including a necrotic/hypoxic core surrounded by intermediate/hypoxic layer and by highly proliferative, welloxygenated and -vascularized outer layer/frontier [27, 28]. Collectively, these complex features of GBM undermine therapeutic strategies targeting single pathways in isolation [47, 48]. HIF1 $\alpha$ expression pattern was heterogenous seen in the hypoxic zone and the normoxic frontier of GBM [49]. Our studies revealed that, to different extents, HIF1 $\alpha$ ablation reduced constitutive activation of both AKT and ERK signaling pathways in U251 cells. Thus, HIF1 $\alpha$ may function as a converging point between these signaling pathways via controlling the expression of PDGF-B, PDGF-D and PDGFR $\alpha$ for the malignancy of GBMs. In addition, based on RNASeq data of U251 cells, HIF1 $\alpha$ may also control IGFIGF1R-AKT and FGF signaling pathways for GBM growth and invasion. Thus, HIF1 $\alpha$ is a crucial master transcriptional factor that orchestrates the expression of growth factors, receptors, signal-pathway substrates, and angiogenic factors under conditions of normoxia and physiological hypoxia. Inhibiting or deleting HIF1 $\alpha$ greatly restrains growth advantages exploited by GBM and may disrupt the reciprocal or feedback regulation between PDGFR $\alpha$-PI3K-AKT and EGFR-ERK pathways once targeting them separately [50]. Meanwhile, 
targeting HIF1 $\alpha$ could largely block angiogenesis via inhibiting expression of VEGF, PDGF-B and PDGF-D; the latter two of which may promote angiogenesis through binding VEGFR2 and coreceptor neuropilin 1, respectively $[51,52]$. Taken together, these features provide a rationale for supporting development of HIF1 $\alpha$ targeting therapies, such as echinomycin, for the treatment of GBM.

HIF $1 \alpha$ is normally degraded under conditions of normoxia, although noncanonical mechanisms are known to promote HIF1 $\alpha$ stability regardless of oxygen tension. Our studies provide additional evidence for noncanonical HIF1 $\alpha$ stabilization, as PDGFD and PDGFR $\alpha$ are both required for high HIF1 $\alpha$ accumulation in GBM cells under normoxia. While PDGFD was found to be a hypoxia-induced gene in our study, expression of PDGF RA was only induced by mild hypoxia or normoxia, and AKT activation was only induced under normoxia in GBM cells. Therefore, the paracrine activity of PDGF-B and PDGF-D originating from intermediate/hypoxic middle-layer of GBM via canonical HIF1 $\alpha$ stabilization may trigger the HIF1 $\alpha$ stabilization in the GBM cells located in the oxygen-rich leading edge of the tumor. More importantly, as PDGFD, PDGFR $\alpha$, and HIF1 $\alpha$ were all required for GBM cell growth and invasion under normoxia and in xenografted mice, our work implies that the PDGFD-PDGFR $\alpha$-HIF $1 \alpha$ axis could be an essential event for GBM malignancy, which is predominantly functional under normoxic or mildly hypoxic conditions. The HIF $1 \alpha$ driven PDGFD and PDGFRA transcription in these conditions suggest that HIF $1 \alpha$ promotes a feedforward PDGFD-PDGFR $\alpha$-AKT signaling in the GBM leading edge. Thus, our findings provide mechanistic insight as to how GBM invades to surrounding tissues.

PDGF-A stimulation or overexpression and PDGF-B overexpression in glial or neural progenitors of mice have been demonstrated each acting a driver for gliomalike neoplasm or glioma-genesis in those mouse models [53-55]. However, their roles in the growth and malignancy of human glioma cells including GBM cell lines have not been revealed. We showed here that PDGF-D is a potent growth factor for both human and mouse GBM cells. Whether it is able to initiate glioma-like brain tumors in mice remains to be defined.

PDGF and PDGFR are frequently co-expressed in human glioma cell lines as well as high-grade gliomas [28, 31]. Previous study showed that PDGFB promoter was activated in breast cancer cells by HIF1 $\alpha$ under hypoxia [56]. Consistently, we showed here that HIF1 $\alpha$ induced PDGF-B, as well as PDGF-D, in U251 cells under hypoxia. In addition, our data showed that PDGF-D was unexpectedly as potent as PDGF-A and PDGF-B in U251 cells which predominantly expressed PDGFR $\alpha$, suggesting that PDGF-D may activate PDGFR $\alpha$ via another receptor rather than PDGFR $\beta$. These findings provide important new insights on how PDGF-D promotes GBM pathogenesis.

TP53 mutation is observed in up to 54\% of proneural GBM, a subtype which also displays frequent overexpression of PDGFR $\alpha$ [5]. Mutant P53 often drives chemotherapy resistance to the first-line drug temozolomide and is associated with poor prognosis $[57,58]$. Targeting HIF1 $\alpha$ by liposomal Echinomycin could exert significant therapeutic effects in mouse models of GBM regardless of TP53 mutations. This effectiveness of Echinomycin is consistent with our previous observation that Echinomycin is effective against TP53 mutated AML [59].

\section{Conclusions}

This report is the first to reveal PDGF-D as a potent growth factor for human GBM cells. HIF1 $\alpha$ plays a critical role in constitutive activation of the AKT signaling pathway for GBM growth by controlling expression of PDGF-D and PDGFR $\alpha$ under normoxia and physiological hypoxia. The HIF1 $\alpha$ inhibitor Echinomycin abolishes the HIF1 $\alpha$-PDGFD-PDGFR $\alpha$ feedforward axis for constitutive activation of AKT pathway and therefore provides a novel and potentially effective therapeutic approach for GBM.

\section{Statistical analysis}

All statistical analysis was performed using the SPSS 21.0 statistical software program. Quantitative data were expressed as mean \pm SD. Comparison of two groups was analyzed with student's $\mathrm{T}$ test. Survival between groups was compared with the log-rank test. A value of $p<0.05$ was considered statistically significant.

\section{Abbreviations}

ANB: Adjacent normal brain tissues; cCasp3: Cleaved caspase 3;

ChIP: Chromatin immunoprecipitation assay; CNS: Central nervous system; EGFR: Epithelial growth factor receptor; ERK: Extracellular regulated protein kinases; FASN: Fatty acid synthase; GAPDH: Glyceraldehyde-3-phosphate dehydrogenase; GBM: Glioblastoma multiforme; GLUT1: Glucose transporter type 1; HGG: High-grade glioma; HIF1a: Hypoxia inducible factor subunit alpha; HK2: Hexokinase 2; HRE: Hypoxia-response element; IGFBP2: Insulin like growth factor binding protein 2; LDHA: Lactate dehydrogenase A;

LEM: Liposomal Echinomycin; LGG: Low-grade glioma;

MCT4: Monocarboxylate transporter 4; NSG: NOD-SCID IL-2receptor gamma null; PARP: Poly(ADP-Ribose) polymerase; PDGF: Platelet-derived growth factor; PDGF-A: Platelet-derived growth factor A; PDGF-B: Platelet-derived growth factor B; PDGF-C: Platelet-derived growth factor C; PDGF-D: Plateletderived growth factor D; PDGFRa: Platelet-derived growth factor receptor subunit alpha; PDGFRß: Platelet-derived growth factor receptor subunit beta; PDK1: Pyruvate dehydrogenase kinase 1; PGK1: Phosphoglycerate kinase 1; RTK: Receptor tyrosine kinase; SCD: Stearoyl-CoA desaturase; sgRNA: Small guide RNA; TGCA: The cancer genome atlas; VEGF-A: Vascular endothelial growth factor $A$

\section{Supplementary Information}

The online version contains supplementary material available at https://doi. org/10.1186/s13046-021-02082-7. 
Additional file 1: Figure $\mathbf{S 1}$. Sequencing of $P C R$ products of genomic DNAs of HIF1A knocked out in U251 cells by HIF1A sgRNA. Figure S2. HIF1A KO in U87MG cells inhibits cell growth. A, B. HIF1A KO U87 cells grow slower than WT cells. HIF1A in U87MG cells was knocked out by Cas9-sgRNA method, which was identified by DNA sequencing of PCR product and by Western-blot (A). WT and HIF1A KO U87MG cells were seeded $1 \times 10^{4}$ /well in a 6 -well plate and cultured for 5 days prior to crystal violet staining to observe colony growth (B). C. NSG mice implanted with HIF1A KO U87MG cells survive longer than WT U251 cells. NSG mice were intracranially implanted with HIF1A KO or WT U87MG cells $\left(5 \times 10^{4} /\right.$ mouse $)$ and Kaplan-Meier survival curves were estimated. Figure S3. HIF1a is required for the expression of PDGFD and PDGFRA under normoxia and mild hypoxia. A. The efficiency of lentiviral infection of primary Glio-1 and Glio-2. Freshly isolated cells from tumor recipients were transduced with high titer lentivirus for HIFIA-sh (mixture of HIFIAsh1 plus HIF1A-sh2) or scrambled control (Sr-sh) by centrifugation at $2500 \mathrm{rpm}$ for $2 \mathrm{~h}$, and were then cultured for additional $30 \mathrm{~h}$ before given to mice. The GFP expression in the sh construct was photographed $24 \mathrm{~h}$ after transduction and represents transfection efficiency. B. Silencing efficiency of HIFTA-sh was determined by fluorescence microscopy of HEK293FT cells $24 \mathrm{~h}$ after co-transfection with either HIF1A-sh plus HIF1aP2A-RFP, or Sr-sh plus HIF1a-P2A-RFP as a parallel control. C. Western blots are shown for U251 WT and HIF1A-KO cells incubated in normoxic or severe hypoxic incubator for 8 or $48 \mathrm{~h}$ before being lysed for Western blot. D. $\mathrm{CoCl}_{2}$ activated the promoter activities of PDGFRA and PDGFD. HEK293FT cells were transfected with PDGFRA or PDGFD promoter GFP reporter plasmids for $8 \mathrm{~h}$, then treated with $\mathrm{CoCl}_{2}$ for an additional $16 \mathrm{~h}$. GFP expression was then visualized by fluorescence microscopy as shown in the top panels, and quantitated by flow cytometry, summarized below. Bar graphs represent mean fluorescence intensity (MFI) readings \pm SD for triplicate wells at each dose. Figure S4. HIF1a, PDGFRa and PDGF-D are frequently co-expressed in GBM. A. Co-expression of HIF1a and PDGFRa in GBM. Microarray of brain tumor with adjacent normal tissues was costained with primary rabbit HIF1a antibody and mouse PDGFRa antibody, and with secondary antibodies goat anti-rabbit Alexa-Fluor 594 and goat anti-mouse Alexa-Fluor 488 after washing away primary antibodies. DAPI was used to visualize nuclei (blue). B. Summary of microarray cases with double positive staining for HIF1a and PDGFRa, which was presented as percentage of total tumor subtype cases. ANB, adjacent normal brain tissue; OD, oligodendrocytoma; $\mathrm{OA}$, oligoastrocytoma; $\mathrm{AA}$, anaplastic astrocytoma; MB, medulloblastoma; EP, ependymoma. Data shown are representative of two independent experiments. C. Correlation of staining intensity for HIF1a with PDGFRa in GBM tissue microarray. IF staining of a 35 cases tissue microarray of GBM and 5 cancer adjacent normal cerebral tissue was performed with PDGFRa and HIF1a antibodies together as described in A. The double positive stains of cases with low, moderate, high, or very high scores were analyzed for the correlation of HIF1a with PDGF Ra. D. Co-expression of HIF1a and PDGF-D in GBM. Sections of brain tumor with adjacent normal brain tissue microarray were co-stained with primary rabbit HIF1a antibody and goat PDGF-D antibody, and with secondary antibodies donkey anti-rabbit Alexa-Fluor 488 and donkey antigoat Alexa-Fluor 594 after washing away primary antibodies. DAPI was used to visualize nuclei (blue). The correlation of staining intensity for HIF1a and PDGF-D are shown. E. Correlation of staining intensity for HIF1 a with PDGFD in GBM tissue microarray. IF staining of a 38-cases tissue microarray of GBM and 6 of normal cerebrum tissues was performed with PDGF-D and HIF1a antibodies as described in D. The double positive stains of 23/38 cases with low, moderate, high, or very high scores were analyzed for the correlation of HIF1a with PDGF-D. Figure S5. TP53 mutation did not affect GBM response to Echinomycin. A. PDGF-DD levels in the medium of HIF1A KO or WT U251 cells. Levels of released PDGF-D protein were measured by ELISA. B. Echinomycin induced apoptosis of U251 cells. Annexin V staining was performed on U251 cells that were treated for $48 \mathrm{~h}$ with different concentrations of Echinomycin. C, D. HIFTA-KO or PDGFRA-KO cells are resistant to Echinomycin. WT, HIFTA-KO or PDGFRA-KO U251 cells were treated with different concentrations of Echinomycin for $72 \mathrm{~h}$ prior to determining cell viability by MTT assay. $\mathrm{E}$. Primary Glio-1 cells have an R273H mutation of TP53 which is also carried by U251 cells. Sequence chromatograms are shown with arrows indicating R273H mutation. Figure S6. Echinomycin reduced the expression of HIF1a target genes. Empty vector-transfected GL261 brain tumor cells were orthotopically transplanted to recipient mice, and the mice were treated with vehicle or LEM as detailed in methods. Twenty-four hours after the final dose, the tumor cells were isolated and the CDNA was used to perform qRT-PCR. Table S1. Characteristics of Clinical Glioma Samples. Table S2. RNA-Seq data of growth factor related genes expressed in WT and HIF1a KO in U251 cells. Table S3. RNA-Seq data of metabolism related genes expressed in WT and HIF1a KO in U251 cells.

\section{Acknowledgments}

Some of the studies were performed when the authors were at the Children's National Medical Center, Washington DC.

\section{Authors' contributions}

$G P, Y a n L$ and $Y W$ designed and performed experiments and prepared data for the manuscript. CB performed in vivo tumor assays and made Lipo-EM and edited the manuscript. PZ performed bioinformatics analysis. PG and DZ provided GBM and glioma tissues. ZM, JC, QC, Qian C and NJ provided with tumor tissue collection and assistances in the experiments. Pan Z, Yang $L$, $Y W$, and Yan $L$ supervised the study. $Y W$ and $Y a n L$ created concepts and wrote the manuscript. The authors read and approved the final manuscript.

\section{Funding}

This study was supported by the grants from National Institute of Health, National Cancer Institute CA171972, CA183030 (Yang Liu), Norman Bethune Program of Jilin University (2015339, G Peng), Program for JLU Science and Technology Innovative Research Team (2017TD-08) and the Fundamental Research Funds for the Central Universities.

\section{Availability of data and materials \\ No applicable.}

\section{Declarations}

\section{Ethics approval and consent to participate}

All procedures involving experimental animals were approved by Institutional Animal Care and Use Committees of the University of Maryland School of Medicine and the First Hospital of Jilin University.

\section{Consent for publication}

No applicable.

\section{Competing interests}

Authors disclosed no potential conflicts of interest.

\section{Author details}

${ }^{1}$ Institute of Translational Medicine, the First Hospital of Jilin University, Changchun, Jilin, China. ${ }^{2}$ Division of Immunotherapy, Department of Surgery and Comprehensive Cancer Center, Institute of Human Virology, University of Maryland School of Medicine, Baltimore, USA. ${ }^{3}$ Department of Neurosurgery, Neuroscience Research Center, The First Hospital of Jilin University, Changchun, Jilin, China. ${ }^{4}$ Beijing Key Laboratory for Genetics of Birth Defects, Beijing Pediatric Research Institute, Beijing Children's Hospital, Capital Medical University, National Cancer for Children's Health, Beijing, China. ${ }^{5}$ Department of Neurosurgery, Beijing Children's Hospital, Capital Medical University, National Cancer for Children's Health, Beijing, China. ${ }^{6}$ OncoC4, Inc., Rockville, MD, USA.

Received: 3 May 2021 Accepted: 24 August 2021 Published online: 01 September 2021

\section{References}

1. Thakkar JP, Dolecek TA, Horbinski C, Ostrom QT, Lightner DD, BarnholtzSloan JS, et al. Epidemiologic and molecular prognostic review of glioblastoma. Cancer Epidemiol Biomark Prev. 2014;23(10):1985-96. https:// doi.org/10.1158/1055-9965.EPI-14-0275.

2. Louis DN, Perry A, Reifenberger G, von Deimling A, Figarella-Branger D, Cavenee WK, et al. The 2016 World Health Organization classification of 
tumors of the central nervous system: a summary. Acta Neuropathol. 2016; 131:803-20.

3. Furnari FB, Fenton T, Bachoo RM, Mukasa A, Stommel JM, Stegh A, et al. Malignant astrocytic glioma: genetics, biology, and paths to treatment. Genes Dev. 2007;21 (21):2683-710. https://doi.org/10.1101/gad.1596707.

4. Ohgaki H, Dessen P, Jourde B, Horstmann S, Nishikawa T, Di Patre PL, et al. Genetic pathways to glioblastoma: a population-based study. Cancer Res. 2004;64(19):6892-9. https://doi.org/10.1158/0008-5472.CAN-04-1337.

5. Verhaak RG, Hoadley KA, Purdom E, Wang V, Qi Y, Wilkerson MD, et al. Integrated genomic analysis identifies clinically relevant subtypes of glioblastoma characterized by abnormalities in PDGFRA, IDH1, EGFR, and NF1. Cancer Cell. 2010;17(1):98-110. https://doi.org/10.1016/j.ccr.2009.12.020

6. Cancer Genome Atlas Research N. Comprehensive genomic characterization defines human glioblastoma genes and core pathways. Nature. 2008; 455(7216):1061-8. https://doi.org/10.1038/nature07385.

7. Parsons DW, Jones S, Zhang X, Lin JC, Leary RJ, Angenendt P, et al. An integrated genomic analysis of human glioblastoma multiforme. Science. 2008:321 (5897):1807-12. https://doi.org/10.1126/science.1164382.

8. Brennan CW, Verhaak RG, McKenna A, Campos B, Noushmehr H, Salama SR, et al. The somatic genomic landscape of glioblastoma. Cell. 2013;155(2): 462-77. https://doi.org/10.1016/j.cell.2013.09.034.

9. Lopez-Gines C, Gil-Benso R, Ferrer-Luna R, Benito R, Serna E, GonzalezDarder J, et al. New pattern of EGFR amplification in glioblastoma and the relationship of gene copy number with gene expression profile. Mod Pathol. 2010;23(6):856-65. https://doi.org/10.1038/modpathol.2010.62.

10. Koschmann C, Zamler D, Mackay A, Robinson D, Wu YM, Doherty R, et al. Characterizing and targeting PDGFRA alterations in pediatric high-grade glioma. Oncotarget. 2016;7(40):65696-706. https://doi.org/10.18632/oncota rget.11602.

11. Szerlip NJ, Pedraza A, Chakravarty D, Azim M, McGuire J, Fang Y, et al. Intratumoral heterogeneity of receptor tyrosine kinases EGFR and PDGFRA amplification in glioblastoma defines subpopulations with distinct growth factor response. Proc Natl Acad Sci U S A. 2012;109(8):3041-6. https://doi. org/10.1073/pnas.1114033109.

12. Ozawa T, Brennan CW, Wang L, Squatrito M, Sasayama T, Nakada M, et al. PDGFRA gene rearrangements are frequent genetic events in PDGFRAamplified glioblastomas. Genes Dev. 2010;24(19):2205-18. https://doi.org/1 0.1101/gad.1972310

13. Puget $S$, Philippe $C$, Bax DA, Job B, Varlet P, Junier MP, et al. Mesenchymal transition and PDGFRA amplification/mutation are key distinct oncogenic events in pediatric diffuse intrinsic pontine gliomas. PLoS One. 2012;7(2): e30313. https://doi.org/10.1371/journal.pone.0030313.

14. Paugh BS, Zhu X, Qu C, Endersby R, Diaz AK, Zhang J, et al. Novel oncogenic PDGFRA mutations in pediatric high-grade gliomas. Cancer Res. 2013;73(20):6219-29. https://doi.org/10.1158/0008-5472.CAN-13-1491.

15. Snuderl M, Fazlollahi L, Le LP, Nitta M, Zhelyazkova BH, Davidson CJ, et al. Mosaic amplification of multiple receptor tyrosine kinase genes in glioblastoma. Cancer Cell. 2011;20(6):810-7. https://doi.org/10.1016/j.ccr.2 011.11.005.

16. Knobbe $C B$, Reifenberger $G$. Genetic alterations and aberrant expression of genes related to the phosphatidyl-inositol-3'-kinase/protein kinase B (Akt) signal transduction pathway in glioblastomas. Brain Pathol. 2003;13(4):50718. https://doi.org/10.1111/j.1750-3639.2003.tb00481.x.

17. Stommel JM, Kimmelman AC, Ying $H$, Nabioullin R, Ponugoti $A H$, Wiedemeyer $\mathrm{R}$, et al. Coactivation of receptor tyrosine kinases affects the response of tumor cells to targeted therapies. Science. 2007;318(5848):28790. https://doi.org/10.1126/science.1142946.

18. Little SE, Popov S, Jury A, Bax DA, Doey L, Al-Sarraj S, et al. Receptor tyrosine kinase genes amplified in glioblastoma exhibit a mutual exclusivity in variable proportions reflective of individual tumor heterogeneity. Cancer Res. 2012;72(7):1614-20. https://doi.org/10.1158/0008-5472.CAN-11-4069.

19. Chakravarty D, Pedraza AM, Cotari J, Liu AH, Punko D, Kokroo A, et al. EGFR and PDGFRA co-expression and heterodimerization in glioblastoma tumor sphere lines. Sci Rep. 2017;7(1):9043. https:/doi.org/10.1038/s41598-017-08940-9.

20. Eskilsson E, Rosland GV, Talasila KM, Knappskog S, Keunen O, Sottoriva A, et al. EGFRvIll mutations can emerge as late and heterogenous events in glioblastoma development and promote angiogenesis through $\mathrm{Src}$ activation. Neuro-Oncology. 2016;18(12):1644-55. https://doi.org/10.1093/ neuonc/now113.

21. Katanasaka Y, Kodera Y, Kitamura Y, Morimoto T, Tamura T, Koizumi F. Epidermal growth factor receptor variant type III markedly accelerates angiogenesis and tumor growth via inducing c-myc mediated angiopoietin-like 4 expression in malignant glioma. Mol Cancer. 2013;12(1): 31. https://doi.org/10.1186/1476-4598-12-31.

22. Ivan $\mathrm{M}$, Kondo $\mathrm{K}$, Yang H, Kim W, Valiando J, Ohh M, et al. HIFalpha targeted for VHL-mediated destruction by proline hydroxylation: implications for $\mathrm{O} 2$ sensing. Science. 2001;292(5516):464-8. https://doi.org/10.1126/science.1 059817.

23. Jaakkola P, Mole DR, Tian YM, Wilson MI, Gielbert J, Gaskell SJ, et al. Targeting of HIF-alpha to the von Hippel-Lindau ubiquitylation complex by O2-regulated prolyl hydroxylation. Science. 2001;292(5516):468-72. https:// doi.org/10.1126/science.1059796.

24. Yu F, White SB, Zhao Q, Lee FS. HIF-1alpha binding to VHL is regulated by stimulus-sensitive proline hydroxylation. Proc Natl Acad Sci U S A. 2001; 98(17):9630-5. https://doi.org/10.1073/pnas.181341498.

25. Wang Y, Liu Y, Malek SN, Zheng P, Liu Y. Targeting HIF1alpha eliminates cancer stem cells in hematological malignancies. Cell Stem Cell. 2011;8(4): 399-411. https://doi.org/10.1016/j.stem.2011.02.006.

26. Wang Y, Liu Y, Tang F, Bernot KM, Schore R, Marcucci G, et al. Echinomycin protects mice against relapsed acute myeloid leukemia without adverse effect on hematopoietic stem cells. Blood. 2014;124(7):1127-35. https://doi. org/10.1182/blood-2013-12-544221.

27. Brat DJ, Castellano-Sanchez AA, Hunter SB, Pecot M, Cohen C, Hammond EH, et al. Pseudopalisades in glioblastoma are hypoxic, express extracellular matrix proteases, and are formed by an actively migrating cell population. Cancer Res. 2004;64(3):920-7. https://doi.org/10.1158/0008-5472.CAN-03-2073.

28. Cantanhede IG, de Oliveira JRM. PDGF family expression in glioblastoma Multiforme: data compilation from ivy glioblastoma atlas project database. Sci Rep. 2017;7(1):15271. https://doi.org/10.1038/s41598-017-15045-w.

29. Li Z, Bao S, Wu Q, Wang H, Eyler C, Sathornsumetee S, et al. Hypoxiainducible factors regulate tumorigenic capacity of glioma stem cells. Cancer Cell. 2009;15(6):501-13. https://doi.org/10.1016/j.ccr.2009.03.018.

30. Jackson EL, Garcia-Verdugo JM, Gil-Perotin S, Roy M, Quinones-Hinojosa A, VandenBerg S, et al. PDGFR alpha-positive B cells are neural stem cells in the adult SVZ that form glioma-like growths in response to increased PDGF signaling. Neuron. 2006;51(2):187-99. https://doi.org/10.1016/j.neuron.2006. 06.012 .

31. Nazarenko I, Hede SM, He X, Hedren A, Thompson J, Lindstrom MS, et al. PDGF and PDGF receptors in glioma. Ups J Med Sci. 2012;117(2):99-112. https://doi.org/10.3109/03009734.2012.665097.

32. Pringle NP, Mudhar HS, Collarini EJ, Richardson WD. PDGF receptors in the rat CNS: during late neurogenesis, PDGF alpha-receptor expression appears to be restricted to glial cells of the oligodendrocyte lineage. Development. 1992;115(2):535-51. https://doi.org/10.1242/dev.115.2.535.

33. Liu KW, Feng H, Bachoo R, Kazlauskas A, Smith EM, Symes K, et al. SHP-2/ PTPN11 mediates gliomagenesis driven by PDGFRA and INK4AVARF aberrations in mice and humans. J Clin Invest. 2011;121(3):905-17. https:// doi.org/10.1172/JCl43690.

34. Hermanson M, Funa $K$, Hartman M, Claesson-Welsh L, Heldin CH, Westermark B, et al. Platelet-derived growth factor and its receptors in human glioma tissue: expression of messenger RNA and protein suggests the presence of autocrine and paracrine loops. Cancer Res. 1992;52(11): 3213-9.

35. Wallmann $T$, Zhang XM, Wallerius $M$, Bolin $S$, Joly AL, Sobocki $C$, et al. Microglia induce PDGFRB expression in Glioma cells to enhance their migratory capacity. iScience. 2018;9:71-83.

36. Li H, Fredriksson L, Li X, Eriksson U. PDGF-D is a potent transforming and angiogenic growth factor. Oncogene. 2003;22(10):1501-10. https://doi.org/1 $0.1038 /$ sj.onc.1206223.

37. LaRochelle WJ, Jeffers M, Corvalan JR, Jia XC, Feng X, Vanegas S, et al. Platelet-derived growth factor D: tumorigenicity in mice and dysregulated expression in human cancer. Cancer Res. 2002;62(9):2468-73.

38. Tchougounova E, Kastemar M, Brasater D, Holland EC, Westermark B, Uhrbom L. Loss of Arf causes tumor progression of PDGFB-induced oligodendroglioma. Oncogene. 2007;26(43):6289-96. https://doi.org/10.103 8/sj.onc. 1210455.

39. Hede SM, Hansson I, Afink GB, Eriksson A, Nazarenko I, Andrae J, et al. GFAP promoter driven transgenic expression of PDGFB in the mouse brain leads to glioblastoma in a Trp53 null background. Glia. 2009:57(11):1143-53. https://doi.org/10.1002/glia.20837.

40. Mendez O, Zavadil J, Esencay M, Lukyanov Y, Santovasi D, Wang SC, et al. Knock down of HIF-1alpha in glioma cells reduces migration in vitro and 
invasion in vivo and impairs their ability to form tumor spheres. Mol Cancer. 2010;9(1):133. https://doi.org/10.1186/1476-4598-9-133.

41. Bergsten E, Uutela M, Li X, Pietras K, Ostman A, Heldin CH, et al. PDGF-D is a specific, protease-activated ligand for the PDGF beta-receptor. Nat Cell Biol. 2001;3(5):512-6. https://doi.org/10.1038/35074588.

42. LaRochelle WJ, Jeffers M, McDonald WF, Chillakuru RA, Giese NA, Lokker NA et al. PDGF-D, a new protease-activated growth factor. Nat Cell Biol. 2001; 3(5):517-21. https://doi.org/10.1038/35074593.

43. Saito Y, Haendeler J, Hojo Y, Yamamoto K, Berk BC. Receptor heterodimerization: essential mechanism for platelet-derived growth factorinduced epidermal growth factor receptor transactivation. Mol Cell Biol. 2001;21(19):6387-94. https://doi.org/10.1128/MCB.21.19.6387-6394.2001.

44. Bailey CM, Liu Y, Peng G, Zhang H, He M, Sun D, et al. Liposomal formulation of HIF-1alpha inhibitor echinomycin eliminates established metastases of triple-negative breast cancer. Nanomedicine. 2020;29:102278. https://doi.org/10.1016/j.nano.2020.102278.

45. Liu Y, Nelson MV, Bailey C, Zhang P, Zheng P, Dome JS, et al. Targeting the HIF-1alpha-IGFBP2 axis therapeutically reduces IGF1-AKT signaling and blocks the growth and metastasis of relapsed anaplastic Wilms tumor. Oncogene. 2021;40(29):4809-19. https://doi.org/10.1038/s41388-021-01907-1.

46. Huang W, Kim HR. Dynamic regulation of platelet-derived growth factor D (PDGF-D) activity and extracellular spatial distribution by matriptasemediated proteolysis. J Biol Chem. 2015;290(14):9162-70. https://doi.org/1 0.1074/jbc.M114.610865.

47. Monteiro AR, Hill R, Pilkington GJ, Madureira PA. The role of hypoxia in glioblastoma invasion. Cells. 2017;6(4). https://doi.org/10.3390/cells6040045.

48. Alexandru O, Horescu C, Sevastre AS, Cioc CE, Baloi C, Oprita A, et al. Receptor tyrosine kinase targeting in glioblastoma: performance, limitations and future approaches. Contemp Oncol (Pozn). 2020;24(1):55-66. https://doi. org/10.5114/wo.2020.94726.

49. Zagzag D, Zhong H, Scalzitti JM, Laughner E, Simons JW, Semenza GL. Expression of hypoxia-inducible factor 1alpha in brain tumors: association with angiogenesis, invasion, and progression. Cancer. 2000;88(11):2606-18. https:// doi.org/10.1002/1097-0142(20000601)88:11<2606:AID-CNCR25>3.0.CO;2-W.

50. McNeill RS, Canoutas DA, Stuhlmiller TJ, Dhruv HD, Irvin DM, Bash RE, et al. Combination therapy with potent PI3K and MAPK inhibitors overcomes adaptive kinome resistance to single agents in preclinical models of glioblastoma. Neuro-Oncology. 2017;19(11):1469-80. https://doi.org/10.1093/ neuonc/nox044.

51. Mamer SB, Chen S, Weddell JC, Palasz A, Wittenkeller A, Kumar M, et al. Discovery of high-affinity PDGF-VEGFR interactions: redefining RTK dynamics. Sci Rep. 2017;7(1):16439. https://doi.org/10.1038/s41598-017-16610-z.

52. Muhl L, Folestad EB, Gladh $\mathrm{H}$, Wang $\mathrm{Y}$, Moessinger $\mathrm{C}$, Jakobsson $\mathrm{L}$, et al. Neuropilin 1 binds PDGF-D and is a co-receptor in PDGF-D-PDGFRbeta signaling. J Cell Sci. 2017;130(8):1365-78. https://doi.org/10.1242/jcs.200493.

53. Bohm AK, DePetro J, Binding CE, Gerber A, Chahley N, Berger ND, et al. In vitro modeling of glioblastoma initiation using PDGF-AA and p53-null neural progenitors. Neuro-Oncology. 2020;22(8):1150-61. https://doi.org/10.1 093/neuonc/noaa093.

54. Rahme GJ, Luikart BW, Cheng C, Israel MA. A recombinant lentiviral PDGFdriven mouse model of proneural glioblastoma. Neuro-Oncology. 2018; 20(3):332-42. https://doi.org/10.1093/neuonc/nox129.

55. Westermark B. Platelet-derived growth factor in glioblastoma-driver or biomarker? Ups J Med Sci. 2014;119(4):298-305. https://doi.org/10.3109/03 009734.2014.970304.

56. Schito L, Rey S, Tafani M, Zhang H, Wong CC, Russo A, et al. Hypoxia-inducible factor 1-dependent expression of platelet-derived growth factor $\mathrm{B}$ promotes lymphatic metastasis of hypoxic breast cancer cells. Proc Natl Acad Sci U S A. 2012;109(40):E2707-16. https://doi.org/10.1073/pnas.1214019109.

57. Muller PA, Vousden KH. Mutant p53 in cancer: new functions and therapeutic opportunities. Cancer Cell. 2014;25(3):304-17. https:/doi.org/10.1016/..ccr.2014.01.021.

58. Wang X, Chen JX, Liu JP, You C, Liu YH, Mao Q. Gain of function of mutant TP53 in glioblastoma: prognosis and response to temozolomide. Ann Surg Oncol. 2014;21(4):1337-44. https://doi.org/10.1245/s10434-013-3380-0.

59. Wang Y, Liu Y, Bailey C, Zhang H, He M, Sun D, et al. Therapeutic targeting of TP53mutated acute myeloid leukemia by inhibiting HIF-1alpha with echinomycin. Oncogene. 2020;39(14):3015-27. https://doi.org/10.1038/s41388-020-1201-z.

\section{Publisher's Note}

Springer Nature remains neutral with regard to jurisdictional claims in published maps and institutional affiliations.

Ready to submit your research? Choose BMC and benefit from:

- fast, convenient online submission

- thorough peer review by experienced researchers in your field

- rapid publication on acceptance

- support for research data, including large and complex data types

- gold Open Access which fosters wider collaboration and increased citations

- maximum visibility for your research: over $100 \mathrm{M}$ website views per year

At BMC, research is always in progress.

Learn more biomedcentral.com/submissions 